\title{
Effect of Pulse Current on Microstructure and Hardness of 316LN Weld Metal
}

\author{
Peng He ${ }^{1}$, a , Keshun Dai ${ }^{1}$, Haokun $\mathrm{Gu}^{1}$, Xuefeng Ruan ${ }^{1}$, Wenkai Xiao ${ }^{1, *}$ \\ ${ }^{1}$ Wuhan University, School of Mechanical and Power, Engineering, Wuhan, China \\ ahepeng5162@foxmail.com, *xiaowenkai@whu.edu.cn
}

Keywords: 316LN ASS; pulse current; weld metal; microstructure; microhardness.

Abstract. 316LN austenitic stainless steel (ASS) has been used as a magnetic support structure for ITER. Pulse current as a new materials processing method, has many remarkable advantages. In this paper, the pulse current was used to treat the 316LN ASS welded metal welded by narrow gap MAG welding. The influence of different pulse current parameters on microstructures and microhardness of $316 \mathrm{LN}$ austenitic stainless steel weld metal was investigated. It was found that the microstructure of 316LN weld metal had a transitional trend from columnar sub-grains to equiaxed grains when the pulse current is increased to 700A. As the pulse current gradually increasing, the microhardness of weld metal first showed a constant trend, then decrease, and finally increase; with the increase of processing time, the microhardness of weld metal increased; with the increase of pressure, the microhardness of weld metal increased too.

\section{Introduction}

In recent years, with the development of science and technology, the requirements for energy are increasing. Nuclear fusion has become the most promising renewable energy technology in the world due to its advantages of abundant resources, no pollution of the environment, and no high radioactive waste [1-5].

316LN ASS is an important material used in the magnetic support structure of ITER. Due to the harsh working environment and particularity, ITER headquarters has a high demand for low-temperature impact toughness of $316 \mathrm{LN}$ welded metal [6-8].

This paper is based on the International Thermonuclear Experimental Reactor of major international science and technology cooperation program. The 316LN ASS weld metal was used as the research object. Before pulse current treatment, the base metal was welded by narrow gap MAG (NG-MAG) arc welding. Through the observation of microstructure and microhardness test of 316LN ASS weld metal after being treated by pulse current, explore the effect of pulse current parameters on the microstructure and microhardness of 316LN ASS weld metal welded by narrow gap MAG welding $[9,10]$.

\section{Experimental materials and methods}

Experimental materials. The 316LN austenitic stainless steel was selected as experimental materials. The base metal was treated with hot rolling, $1050{ }^{\circ} \mathrm{C}$ solution treatment and water quenching process before welding. The weld metal was obtained by NG-MAG arc welding. The filler metal used was ASN 5-1G (AWS/ASME SFA 5.01 ER317L).diameter 1.2mm.

Main experimental equipment. The welding equipment of this experiment was a narrow gap melting gas protection automatic welding system shown in Fig 1. The pulse current treatment equipment used in this experiment was SPS 320 MKII discharge plasma sintering equipment. The pulse current heat treatment device was shown in Fig 2. 


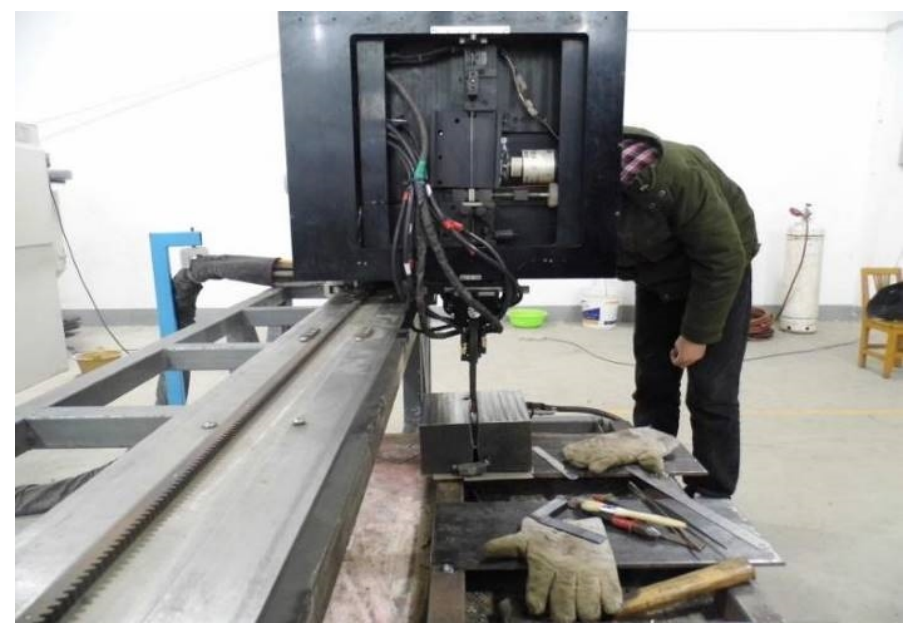

Fig 1. Narrow gap MIG gas shielded automatic welding system

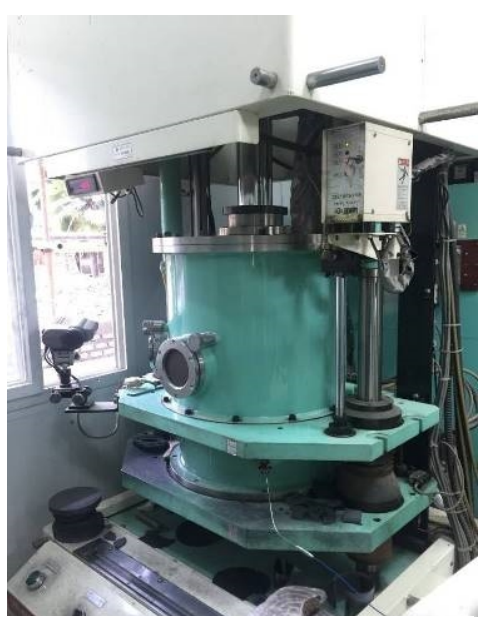

Fig 2.Pulse current heat treatment equipment

Experimental parameters. In this experiment, the experimental parameters were displayed in Tab 1.

Tab 1. Experimental parameters of pulse current treatment

\begin{tabular}{|c|c|c|c|}
\hline number & Pulse current parameter & number & Pulse current parameter \\
\hline $\mathbf{1}$ & No processing & $\mathbf{6}$ & $600[\mathrm{~A}]+30[\mathrm{~min}]+$ no pressure \\
\hline $\mathbf{2}$ & $200[\mathrm{~A}]+5[\mathrm{~min}]+$ no pressure & $\mathbf{7}$ & $600[\mathrm{~A}]+30[\mathrm{~min}]+3[\mathrm{kN}]$ \\
\hline $\mathbf{3}$ & $400[\mathrm{~A}]+5[\mathrm{~min}]+$ no pressure & $\mathbf{8}$ & $600[\mathrm{~A}]+30[\mathrm{~min}]+5[\mathrm{kN}]$ \\
\hline $\mathbf{4}$ & $600[\mathrm{~A}]+5[\mathrm{~min}]+$ no pressure & $\mathbf{9}$ & $700[\mathrm{~A}]+30[\mathrm{~min}]+$ no pressure \\
\hline $\mathbf{5}$ & $600[\mathrm{~A}]+10[\mathrm{~min}]+$ no pressure & & \\
\hline
\end{tabular}

\section{Result and discussion}

Microstructure analysis. The microstructure of untreated 316LN ASS weld metal showed elongated columnar sub-grains shown in Fig 3. The microstructure of weld metal after being treated with 200A and $5 \mathrm{~min}$ pulse current had no significant change as shown in Fig 4. The microstructure of weld metal after being treated with 400A and 5min pulse current was slender columnar sub-grains as shown in Fig 5.

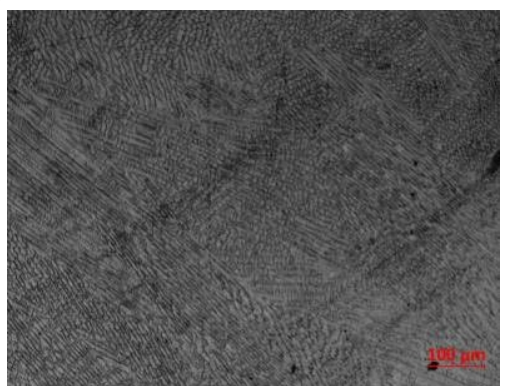

Fig 3. No processing

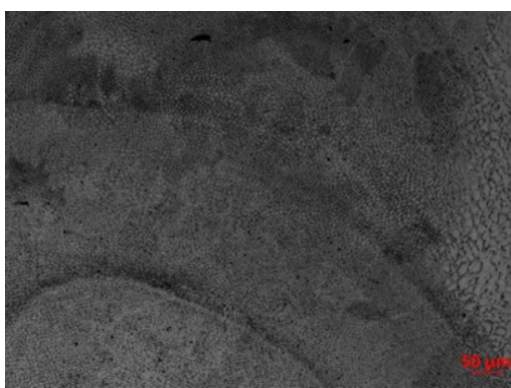

Fig 4. $200 \mathrm{~A}+5 \mathrm{~min}+$ no pressure

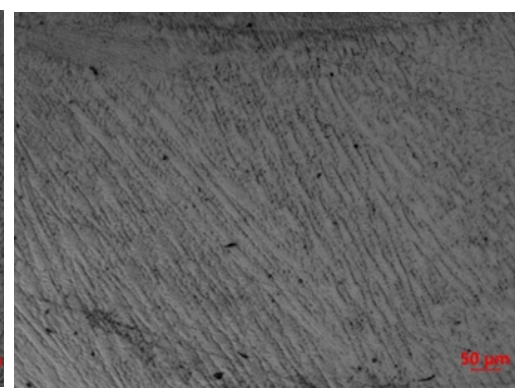

Fig 5. $400 \mathrm{~A}+5 \mathrm{~min}+$ no pressure

Fig 6 showed the microstructure of weld metal after being treated with 600A and 5min pulse current treatment. The original austenite grain boundary appears in the elongated columnar structure in the weld metal. Fig 7 showed that the microstructure of weld metal treated by pulsed current of $600 \mathrm{~A}$ and $10 \mathrm{~min}$ is elongated columnar crystal structure. Fig 8 showed that the microstructure of the weld metal treated by pulsed current of $600 \mathrm{~A}$ and 30min was still a thin columnar structure. 


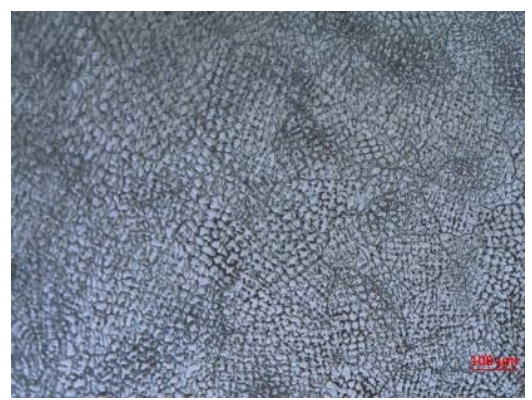

Fig 6. 600A+5min+ no pressure

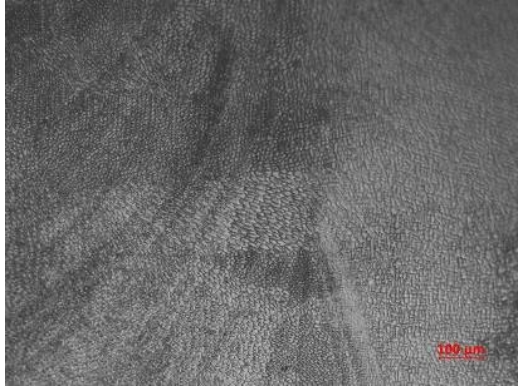

Fig 7. 600A+10min+ no pressure Fig 8. 600A+30min+ no pressure

Fig 9 showed that the microstructure of the weld metal treated by the pulsed current of $600 \mathrm{~A}$, $30 \mathrm{~min}$ and $3 \mathrm{kN}$ had not changed significantly. Fig 10 showed that the microstructure of the weld metal treated by the pulsed current of $600 \mathrm{~A}, 30 \mathrm{~min}$ and $5 \mathrm{kN}$ was elongated columnar crystalline structure. Fig 11 showed the microstructure of the weld metal treated by $700 \mathrm{~A}$ and $30 \mathrm{~min}$. Original austenite grain boundaries of large angle was observed and the microstructure 316LN ASS weld metal had a transition trend from columnar sub-grains to equiaxed grains.

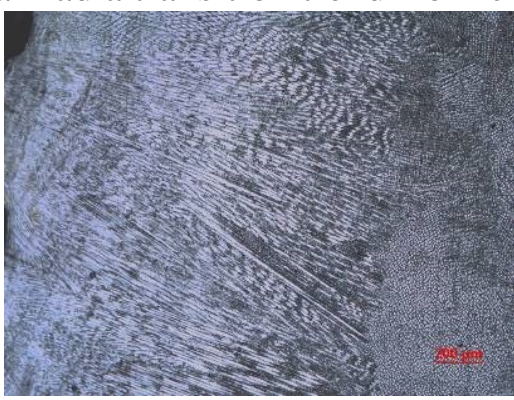

Fig 9. $600 \mathrm{~A}+30 \mathrm{~min}+3 \mathrm{kN}$

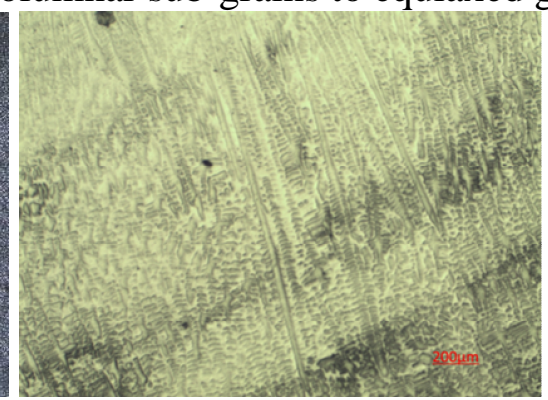

Fig 10. $600 \mathrm{~A}+30 \mathrm{~min}+5 \mathrm{kN}$

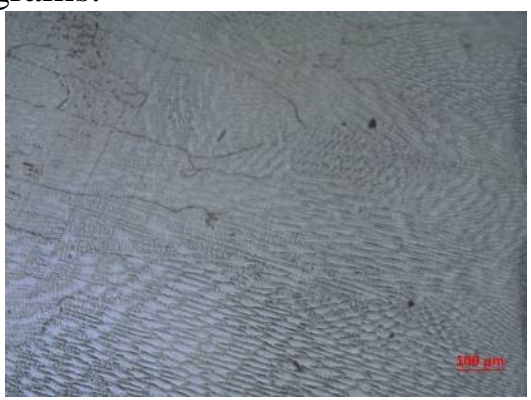

Fig 11. 700A+30min+ no pressure

Microhardness test. As shown in Fig. 12, the microhardness of the sample treated with 200A-5min and 400A-5min did not produce any significant change compared with the original weld. The micro-hardness of the sample treated with 600A-5min has been a decline compared with the original weld.

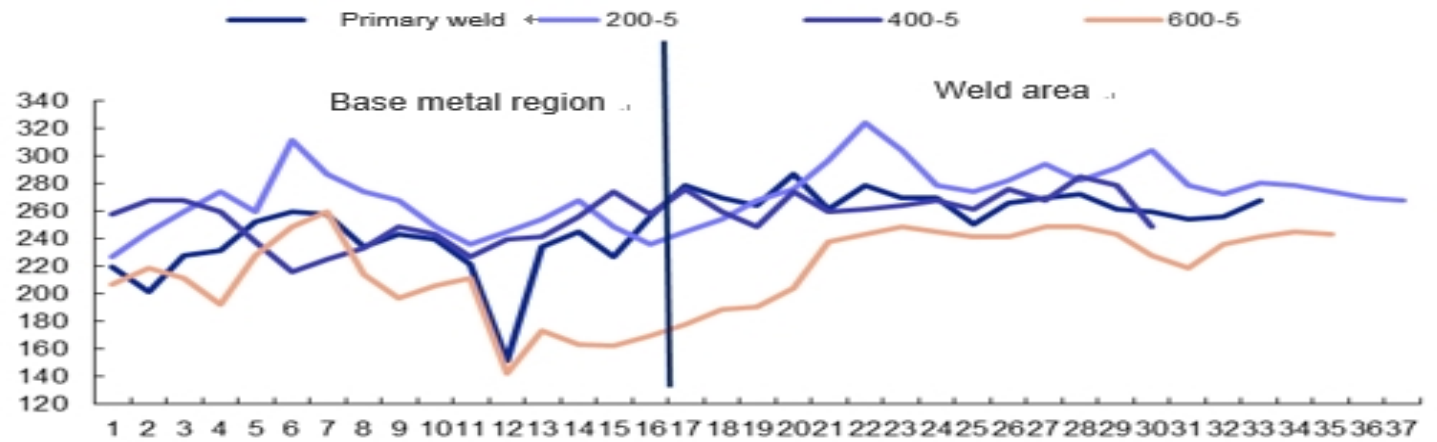

Fig 12. Effect of different current sizes on microhardness.

As shown in Fig. 13, the microhardness of the $316 \mathrm{LN}$ austenitic stainless steel welded metal increases as the processing time increases. Among them, the microhardness of the weld metal treated with 700A-30min treatment appeared a greater rise.

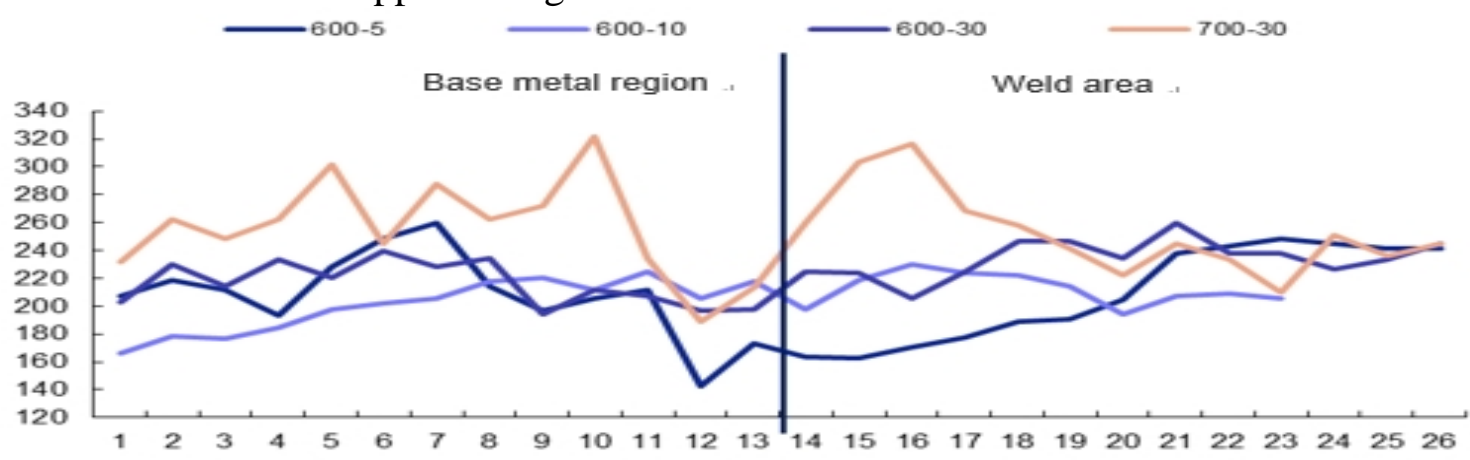

Fig 13.Effect of different pulse current treatment time on microhardness 
As shown in Fig. 14, as the pressure increases, the microhardness of the 316LN austenitic stainless steel welded metal increases.

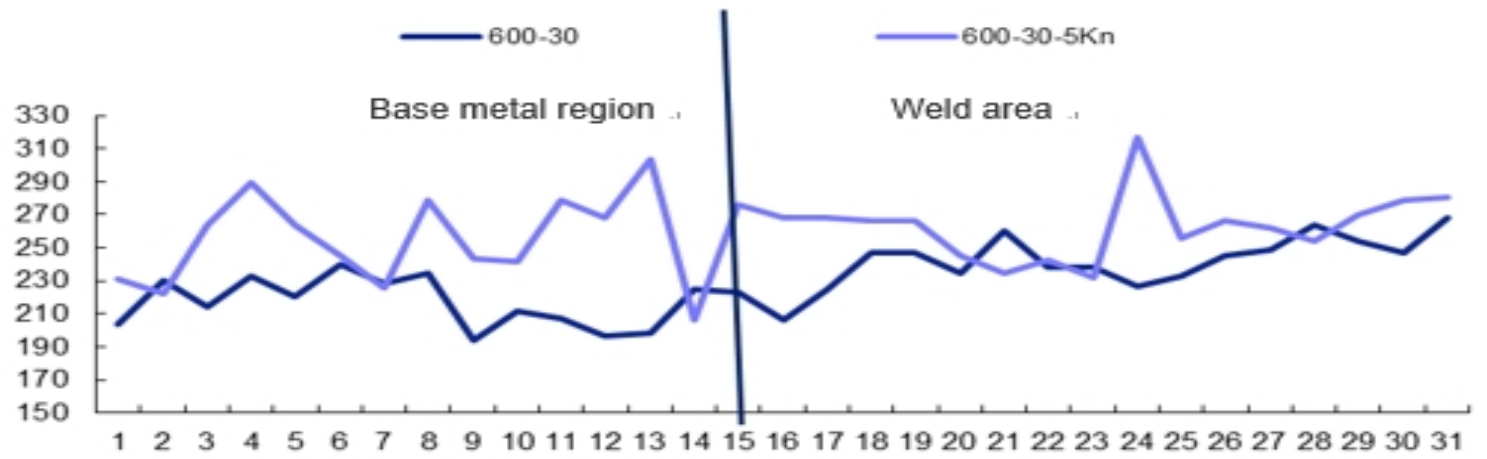

Fig 14.Effect of different pulse current treatment pressure on microhardness

\section{Conclusions}

In this paper, the change of microstructure and microhardness of $316 \mathrm{LN}$ weld metal after being treated with different pulse current parameters has been studied, and the following experimental conclusions have been obtained:

(1) When pulse current was set to 200A, 400A and 600A, the microstructure of 316LN ASS weld metal did not show significant changes; when the current was increased to 700A, the microstructure of 316LN ASS weld metal had a transition trend from columnar sub-grains to equiaxed grains.

(2) When the pulse current was set to 200A and 400A, the microhardness of 316LN austenitic stainless steel welding metal did not change significantly; when the pulse current increased to 600A, the microhardness of welded metal decreased; when the pulse current increased to 700A, microhardness has increased. With the increase of processing time, the microhardness of weld metal increased; with the increase of pressure, the microhardness of weld metal increased.

\section{References}

[1] Petrecca G. Energy Conversion \& Management, 2014:25-29.

[2] Robert S. Pindyck. Mit Press Books, 1979, 1(359):76-83.

[3] Tagare, Digambar M. Soviet Atomic Energy, 2011, 40(6):602-603.

[4] Hirsch R L, Rice W L R. Environmental Conservation, 1974, 1(4):251-262.

[5] Hanson A. Endocrinology, 2006, 147(9):4410-8.

[6] Shankar V, Gill T P S, Mannan S L and Sundaresan S. Sadhana, 2003, 28(3-4):359-382.

[7] Takalo T, Suutala N, Moisio T. Metallurgical Transactions A, 1979, 10(8):1173-1181.

[8] Honeycombe R W K, Mehl R F. Metallurgical Transactions A, 1976, 7(7):915-936.

[9] Tokita M. Journal of the Research Association of Powder Technology Japan, 2010, 30:790-804.

[10] Ono H, Obata R, Teramoto T, Matsuda T. Quarterly Journal of the Japan Welding Society, 1983, 1:83-90. 